Published in final edited form as:

J Am Soc Hypertens. 2014 August ; 8(8): 604-606. doi:10.1016/j.jash.2014.07.003.

\title{
The CardioRenal Metabolic Syndrome
}

\author{
Adam Whaley Connell $1,3,4,5,6$ and James R. Sowers ${ }^{1,2,4,5,6}$ \\ ${ }^{1}$ Department of Internal Medicine, University of Missouri-Columbia School of Medicine \\ ${ }^{2}$ Department of Medical Pharmacology, University of Missouri-Columbia School of Medicine \\ ${ }^{3}$ Division of Nephrology and Hypertension, the Harry S Truman Memorial Veterans Hospital, \\ Columbia, MO \\ ${ }^{4}$ Divison of Endocrinology and Metabolism, the Harry S Truman Memorial Veterans Hospital, \\ Columbia, MO \\ ${ }^{5}$ Divison of Diabetes Cardiovascular Center, the Harry S Truman Memorial Veterans Hospital, \\ Columbia, MO \\ ${ }^{6}$ Harry S Truman Memorial Veterans Hospital, Columbia, MO
}

\begin{abstract}
Over-nutrition and the development of obesity contribute to a group of interactive maladaptive cardiovascular and kidney disease risk factors that include insulin resistance, hypertension, and dyslipidemia that constitute the CardioRenal Metabolic Syndrome (CRS). The emerging pandemic of obesity is thought to be triggered by sociologic/environmental factors that include increasing sedentary lifestyle with physical inactivity and excess compact caloric consumption. Childhood obesity is an increasingly common cause of insulin resistance and attending associated long-term cardiovascular disease (CVD), metabolic and renal complications including hypertension, pre-diabetes (e.g. impaired glucose tolerance), fatty liver disease overt type 2 diabetes mellitus and chronic kidney disease (CKD). While obesity is the central driver in this constellation of risk factors for heart and kidney disease, it is increasingly recognized both CVD and CKD risk factors occur in aggregate in a significant portion of the population. There is currently a vigorous discussion on whether the risk is cumulative, additive, or synergistic but most experts agree the risk compounds with increasing number of risk factors for both CVD and CKD.
\end{abstract}

In this context, identifying populations in the earlier stages of disease progression as a tool for CVD and CKD risk prediction as become increasingly important. Heart disease and the presence of heart failure are present in more than five million persons in the United States, accounting for nearly $\$ 40$ billion in annual health care costs. The most common form of heart failure is that with preserved ejection fraction (e.g. diastolic dysfunction), and is

(C) 2014 American Society of Hypertension. Published by Elsevier Inc. All rights reserved.

Corresponding Author: James R Sowers, MD D109 HSC Diabetes Center One Hospital Dr Columbia, MO 65212, USA sowersj@ health.missouri.edu (T) 573-882-0999 (F) 573-884-5530.

Publisher's Disclaimer: This is a PDF file of an unedited manuscript that has been accepted for publication. As a service to our customers we are providing this early version of the manuscript. The manuscript will undergo copyediting, typesetting, and review of the resulting proof before it is published in its final citable form. Please note that during the production process errors may be discovered which could affect the content, and all legal disclaimers that apply to the journal pertain. 
increasing in Westernized cultures. Both overweight/obesity and insulin resistance are prominent risk factors for this form of heart failure and occur before the onset of contractile dysfunction. In this metabolic form of heart disease, diastolic dysfunction is characterized by relaxation abnormalities with a diminution in the ability of the left ventricle to fill with blood during early diastolic filling.

The presence of insulin resistance appears to play an important role in obesity-related heart failure. Impaired insulin metabolic signaling, reduced bioavailable nitric oxide (NO), and increased oxidant stress and inflammation all play a role in maladaptive myocardial tissue remodeling and interstitial fibrosis that contribute to impairments in diastolic relaxation. Patients with diastolic dysfunction are increasingly recognized as an important population to target for prevention of future loss of systolic function with lifestyle changes (weight reduction and exercise) in conjunction with strategies to treat hypertension and insulin resistance especially in the presence of associated kidney disease.

Recent work has highlighted a strong association between obesity and the presence of proteinuria and/or reduced kidney function with or without the presence of insulin resistance. To this point, there exists a strong relationship between increases in body mass index and risk for progression of kidney disease with requirement for renal replacement therapy (e.g. dialysis or transplantation). The interaction between obesity and other CKD risk factors has been partly elucidated by several observational and mechanistic studies. One potential mechanism by which obesity promotes kidney disease is through glomerular hyper-filtration. Evidence support this early functional abnormality exists not only in those with diabetes but importantly in those with insulin resistance (e.g. pre-diabetes) and recent data suggest a very strong relationship between glomerular hyper-filtration and adiposity and hypertension. In this context, recent work further support this relationship is strengthened in composite with three or more risk factors for the CRS. Preclinical work support this relationship with hyper-filtration is dependent on increases in visceral adiposity (elevated leptin levels) and visceral fat production of inflammatory adipokines and possibly factors that stimulate adrenal glomerulosa aldosterone production. While other factors may influence disease progression such as systemic and kidney tissue inflammation and oxidative stresswhich, in turn, may determine to what extent this hyper-filtration translates into future glomerular and tubulointerstitial fibrosis and progressive kidney disease.

The obesity epidemic in the United States and exponential growth of heart and kidney disease, have paralleled the substantial increase consumption of high-fructose corn syrup which has increased substantially in the past three decades. Indeed, high-fructose corn syrup now also represents $40 \%$ of the non-calorie free sweeteners in foods. Recent evidence supports the notion that high-fructose corn syrup sweetened soda consumption is associated with increased proteinuria/ kidney disease as well as heart disease and diabetes. One potential mechanisms by which increased consumption of a high-fructose corn syrup diet causes heart and kidney disease is through increases in uric acid production. The metabolism of fructose increases the degradation of nucleotides and the associated synthesis of uric acid. In rodent models, fructose associated hyperuricemia produces CRS with associated glomerular hyper-filtration, endothelial dysfunction, and myocardial tissue remodeling (Fig 1). 
The relationship between obesity, kidney disease and heart failure with preserved systolic function is an increasingly recognized epidemic in industrialized countries. We refer to this constellation of metabolic risk factors as the CardioRenal Metabolic Syndrome which is an extension of the prior use of this terminology to refer to coexistent heart and kidney disease. The current use of this terminology considers obesity, especially central obesity as a pivotal factor in the development of insulin resistance, metabolic dyslipedemia, and associated kidney and heart disease.

\section{References}

1. Ogden CL, Carroll MD, Curtin LR, McDowell MA, Tabak CJ, Flegal KM. Prevalence of overweight and obesity in the United States,1999-2004. JAMA. 2006; 295:1549-1555. [PubMed: 16595758]

2. McGee DL. Diverse Populations Collaboration: Body mass index and mortality: a meta-analysis based on person-level data from twenty-six observational studies. Ann Epidemiol. 2005; 15:87-97. [PubMed: 15652713]

3. Weiss R, Dziura J, Burgert TS, Tamborlane WV, Taksali SE, Yeckel CW, Allen K, Lopes M, Savoye M, Morrison J, Sherwin RS, Caprio S. Obesity and the metabolic syndrome in children and adolescents. N Engl J Med. 2004; 350(23):2362-2374. [PubMed: 15175438]

4. Dagenais GR, Yi Q, Mann JF, Bosch J, Pogue J, Yusuf S. Prognostic impact of body weight and abdominal obesity in women and men with cardiovascular disease. Am Heart J. 2005; 149:54-60. [PubMed: 15660034]

5. Coresh J, Selvin E, Stevens LA, Manzi J, Kusek JW, Eggers P, Van Lente F, Levey AS. Prevalence of chronic kidney disease in the United States. JAMA. 2007; 298:2038-2047. [PubMed: 17986697]

6. Hsu CY, McCulloch CE, Iribarren C, Darbinian J, Go AS. Body mass index and the risk for endstage renal disease. Ann Intern Med. 2006; 144:21-28. [PubMed: 16389251]

7. Chen J, Muntner P, Hamm LL, Jones DW, Batuman V, Fonseca V, Whelton PK, He J. The metabolic syndrome and chronic kidney disease in U.S. adults. Ann Intern Med. 2004; 140:167174. [PubMed: 14757614]

8. Johnson RJ, Segal MS, Sautin Y, Nakagawa T, Feig DI, Kang DH, Gersch MS, Benner S, SánchezLozada LG. Potential role of sugar (fructose) in the epidemic of hypertension, obesity, and the metabolic syndrome, diabetes, kidney disease, and cardiovascular disease. Am J Clin Nutr. 2007; 86:899-906. [PubMed: 17921363]

9. Owan TE, Hodge DO, Herges RM, Jacobsen SJ, Roger VL, Redfield MM. Trends in prevalence and outcome of heart failure with preserved ejection fraction. N Engl J Med. 2006; 355(3):251-9. [PubMed: 16855265]

10. House AA, Haapio M, Lassus J, Bellomo R, Ronco C. Therapeutic Strategies for Heart Failure in Cardiorenal Syndromes. Am J Kid Dis. 2010; 56(4):759-773. [PubMed: 20557988]

11. Sowers JR, Whaley-Connell A, Hayden MR. The Role of Overweight and Obesity in the Cardiorenal Syndrome. Cardiorenal Med. Jan. 2011; 1(1):5-12. [PubMed: 22258461] 


\section{CardioRenal Metabolic Syndrome}

- Central obesity

- Insulin resistance

- Hypertension

- Metabolic dyslipidemia

- Proteinuria and/or reduced kidney function

\section{Dysfunctional} adipose tissue

Low-grade inflammation

- Reduced adiponectin

- Increased adipokines

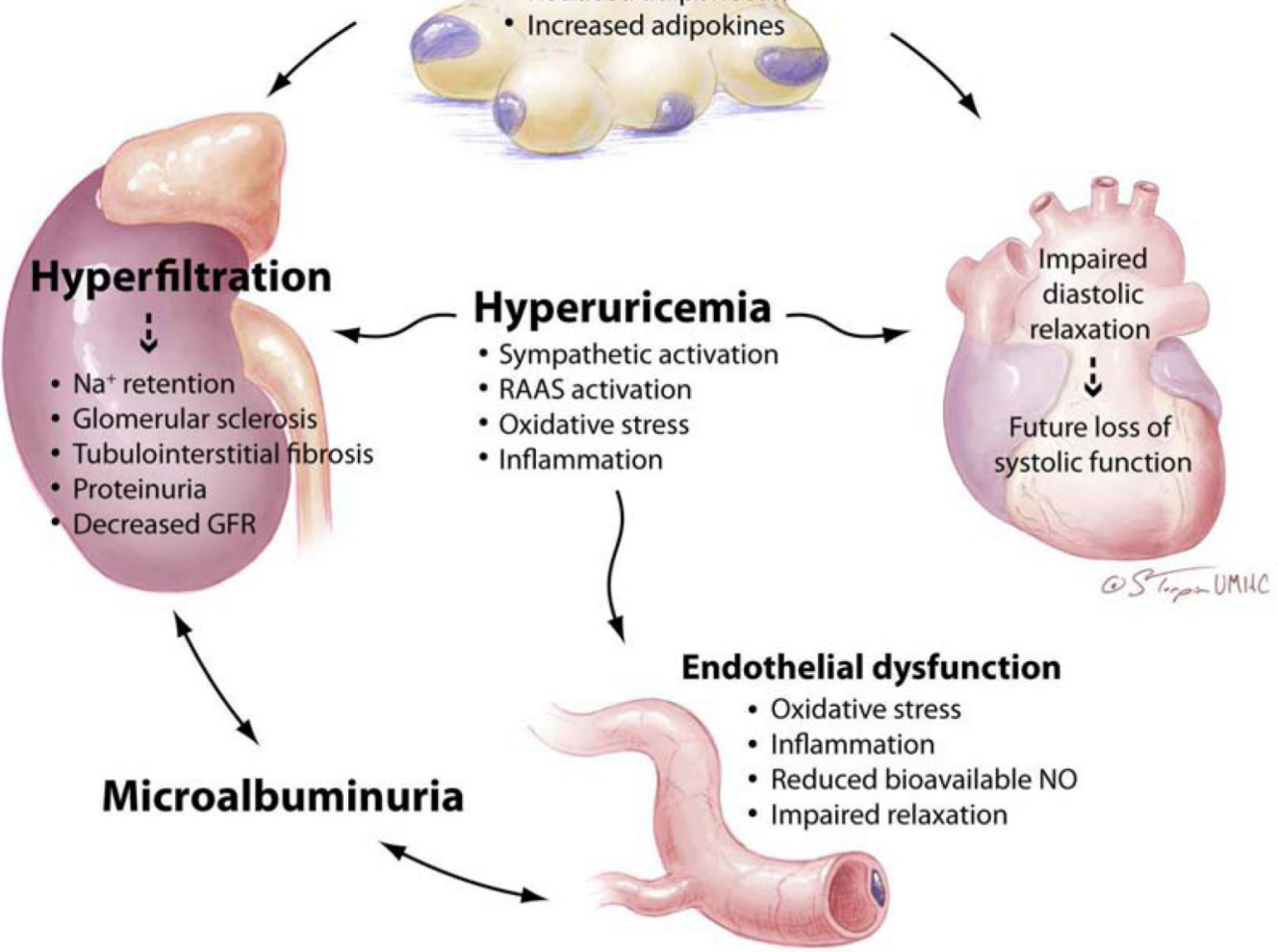

Fig 1.

The inter-relationship between adiposity and maladaptive changes in the heart and kidneys in the CardioRenal Metabolic Syndrome (CRS). GFR, glomerular filtration rate; $\mathrm{Na}^{+}$, sodium; NO, nitric oxide; RAAS, renin-angiotensin-aldosterone system. Adapted with permission from Sowers et al. Cardiorenal Med. 2011;1:5-12. 


\section{Table 1}

Components of the CardioRenal Metabolic Syndrome (11)

\begin{tabular}{ll}
\hline 1. & Central Obesity \\
2. Insulin resistance \\
3. Hypertension \\
4. Metabolic dyslipidemia (Low HDL, high triglycerides and increased small dense LDL particles) \\
5. \\
\hline
\end{tabular}

